\title{
Core outcomes for randomized trials and core information for clinical decision-making: implications for outcome selection
}

\author{
Angus McNair ${ }^{1 *}$, Robert Whistance ${ }^{1}$, Rachel Forsythe ${ }^{1}$, Rhiannon Macefield ${ }^{1}$, Sara Brookes ${ }^{1}$, Jane Blazeby ${ }^{1,2}$, \\ CONSENSUS-CRC working group ${ }^{1}$
}

From 3rd International Clinical Trials Methodology Conference

Glasgow, UK. 16-17 November 2015

\section{Introduction}

Core outcomes sets (COS) are an agreed minimum group of outcomes to measure in trials. Core information sets (CIS) are defined as the agreed minimum information required for clinical decision-making. Theoretically, these concepts should be closely aligned, however, there is no evidence that COSs adequately inform CISs. This study compared COS and CIS for colorectal cancer (CRC) surgery.

\section{Methods}

All potential outcomes/information of importance were identified through systematic literature reviews, reviews of hospital information leaflets and patient interviews. This informed Delphi questionnaires which asked stakeholders (patients, surgeons and nurses) from a sample of UK CRC centres to rate the importance of 1) outcomes and 2) information on a five-point Likert scale. Respondents were resurveyed following feedback from stakeholder groups. Outcomes/information rated as less important were discarded according to pre-defined criteria. The final COS and CIS was agreed at separate international consensus meetings with professionals and patients. Comparisons were made between core set items.

\section{Results}

Data sources identified 1216 outcome/information of CRC surgery that informed a 116 item questionnaire. Centre response rates were 79\% (64/81), including 93 surgeons and 11 clinical nurse specialists, and 97 of 267 patients. Stakeholders prioritized 51 and 23 items in the

${ }^{1}$ University of Bristol, Bristol, UK

Full list of author information is available at the end of the article first and second surveys, and consensus meetings reduced this to a 9 item COS and 10 item COS. The sets were identical apart from additional length of hospital stay information.

\section{Conclusion}

Stakeholders largely agreed on the content of COS and CIS in CRC, but further research is needed to demonstrate this in other settings.

\section{Authors' details}

'University of Bristol, Bristol, UK. ${ }^{2}$ University Hospitals Bristol NHS Foundation Trust, Bristol, UK.

Published: 16 November 2015

doi:10.1186/1745-6215-16-S2-P65

Cite this article as: McNair et al: Core outcomes for randomized trials and core information for clinical decision-making: implications for outcome selection. Trials 2015 16(Suppl 2):P65.

Submit your next manuscript to BioMed Central and take full advantage of:

- Convenient online submission

- Thorough peer review

- No space constraints or color figure charges

- Immediate publication on acceptance

- Inclusion in PubMed, CAS, Scopus and Google Scholar

- Research which is freely available for redistribution 